\title{
Níveis de cloro para codornas japonesas na fase de postura
}

\author{
Roseane Madeira Bezerra ${ }^{1}$, Ednardo Rodrigues Freitas ${ }^{2}$, Nádia de Melo Braz ${ }^{1}$, Regina \\ Patrícia de Souza Xavier ${ }^{3}$, Nadja Naiara Pereira Farias ${ }^{3}$, Newton Lima Sá ${ }^{3}$
}

\footnotetext{
${ }^{1}$ Mestranda do Programa de Pós-graduação em Zootecnia - UFC/Fortaleza. Bolsista da Capes.

2 Departamento de Zootecnia - CCA/UFC/Fortaleza.

${ }^{3}$ Curso de graduação em Zootecnia - UFC/Fortaleza.
}

RESUMO - Com o objetivo de avaliar os efeitos de quatro níveis de cloro sobre o desempenho e a qualidade de ovos de codornas japonesas na fase de produção, 288 codornas com 17 semanas de idade foram distribuídas em delineamento inteiramente casualizado, com seis tratamentos, oito repetições e seis aves por unidade experimental. Os níveis de cloro avaliados foram 0,$07 ; 0,12 ; 0,17 ; 0,22 ; 0,27$ e $0,32 \%$ e os parâmetros de desempenho e qualidade dos ovos foram: consumos de ração e água, porcentagem de postura, peso e massa de ovos, conversão alimentar, umidade das excretas, coeficientes de digestibilidade da matéria seca (CDMS), nitrogênio (CDN) e energia bruta (CDEB), energia metabolizável aparente (EMA) e aparente corrigida (EMAn), unidade Haugh, porcentagens de albúmen, gema e casca. Os níveis de cloro não influenciaram significativamente nenhuma dessas variáveis, entretanto, a gravidade específica aumentou linearmente com o acréscimo de cloro na ração. Pode-se recomendar que rações para codornas japonesas na fase de produção sejam formuladas com níveis de cloro de até $0,32 \%$.

Palavras-chave: balanço eletrolítico, cloreto de amônia, minerais, produção de ovos, sal comum

\section{Chlorine levels for Japanese quails during the egg-laying period}

\begin{abstract}
In order to evaluate the effects of chlorine levels on performance and egg quality of Japanese quails during the production phase, 288 quails with seventeen weeks of age were distributed in a completely randomized design with six treatments, eight replicates and six birds experimental unit. Chlorine levels were: $0.07,0.12,0.17,0.22,0.27$ and $0.32 \%$. Performance and egg quality parameters evaluated were: feed intake (g/bird/day), water consumption (mL/bird/day), production (\%), egg weight (g), egg mass (g/bird/day), feed conversion (g/g), moisture of excreta, digestibility of dry matter, coefficient of nitrogen, coefficient of gross energy, apparent metabolizable energy, corrected apparent metabolizable energy, Haugh unit, percentages of albumen, yolk and shell. Chlorine levels did not significantly influence any of those variables; however, the specific gravity increased linearly with the addition of chlorine in the feed. It is recommended that diets for Japanese quails during the production phase be formulated with clorine levels of up to $0.32 \%$.
\end{abstract}

Key Words: ammonium chloride, electrolyte balance, minerals, production, salt

\section{Introdução}

O cloro é encontrado nas células, nos fluidos extracelulares do organismo, principalmente na forma de cloreto de sódio e cloreto de potássio, e no suco gástrico, como ácido clorídrico. É um nutriente de baixo custo e sua manipulação pouco influencia o custo da ração, porém, devido às suas importantes funções metabólicas, torna-se necessário seu suprimento nos níveis e balanço adequados para ótimo crescimento (Rondón et al., 2000).

O cloro, juntamente com o sódio e o potássio, é importante, não somente para o equilíbrio acidobásico, mas também por influenciar o crescimento, o apetite, o desenvolvimento ósseo, a resposta ao estresse térmico e o metabolismo de certos nutrientes, como aminoácidos, minerais e vitaminas, influenciando no desempenho das aves na fase inicial e, posteriormente, na fase de produção (Rodrigues et al., 2008).

No Brasil, durante muito tempo, vem sendo utilizados nas formulações de rações para codornas dados de exigências nutricionais contidos em publicações internacionais, como o National Research Council (NRC, 1994). Essa prática tem sido considerada inadequada ao desenvolvimento da atividade, visto que as condições climáticas brasileira e o material genético atualmente utilizado são bem diferentes. Diante da situação nos últimos anos, pesquisadores brasileiros têm buscado determinar as exigências para codornas nas diferentes fases de produção. 
Para codornas japonesas (Coturnix coturnix japonica) em postura, têm sido preconizados níveis de $0,14 \%$ de $\mathrm{Cl}$ na ração (NRC, 1994). Em geral, os criadores de codornas formulam rações com níveis de 0,25 a 0,30\% de sal comum, segundo tabela de composição de ingredientes de Rostagno et al. (2005), para dietas contendo $20 \%$ de proteína bruta e formuladas à base de milho e farelo de soja (Pizzolante et al., 2006). No entanto, são escassas as pesquisas que confirmam as recomendações de cloro nas rações para essas aves.

Diante do exposto, o objetivo na realização deste trabalho foi avaliar os efeitos do nível de cloro na ração sobre o desempenho e a qualidade dos ovos de codornas japonesas na fase de produção.

\section{Material e Métodos}

O experimento foi conduzido no período de 12 de março a 25 de junho de 2008, totalizando 105 dias, divididos em cinco períodos de 21 dias. Foram utilizadas 288 codornas japonesas com 119 dias de idade e peso médio de $169 \mathrm{~g}$. As aves foram distribuídas em delineamento inteiramente casualizado com seis níveis de cloro (tratamentos) e oito repetições de seis aves por unidade experimental.

As rações foram formuladas para a fase de postura e continham 0,07; 0,12; 0,17; 0,22; 0,27 e 0,32\% de cloro. Foram formuladas à base de milho e farelo de soja (Tabela 1) para serem isonutritivas, segundo as recomendações nutricionais em energia metabolizável, proteína bruta, aminoácidos, cálcio e fósforo constantes no NRC (1994), exceto quanto aos níveis de cloro. Como dados de composição de alimentos foram considerados os valores descritos por Rostagno et al. (2005) e obtidos em análises.

Os níveis de sódio (Na) e de potássio (K) nas rações foram mantidos constantes em todas as rações considerando as recomendações do NRC (1994). O nível de potássio recomendado foi obtido com o uso do farelo de soja como principal fonte de proteína e os de cloro, pela inclusão de cloreto de sódio $(\mathrm{NaCl})$ e cloreto de amônia $\left(\mathrm{NH}_{4} \mathrm{Cl}\right)$, enquanto o bicarbonato de sódio $\left(\mathrm{NaHCO}_{3}\right)$ foi utilizado para manter os mesmos níveis de sódio nas rações.

O balanço eletrolítico (BE) das rações experimentais foi calculado considerando os valores percentuais dos eletrólitos segundo Mongin (1980), por meio da seguinte fórmula:

$\mathrm{BE}=\% \mathrm{Na}^{+} \times 10000 / 22,990 *+\% \mathrm{~K}^{+} \times 10000 / 39,102 *$ $\% \mathrm{Cl}^{-} \times 10000 / 35,453 *$

em que: (* Equivalente grama do $\mathrm{Na}^{+}, \mathrm{Cl}^{-}$e $\mathrm{K}^{+}$, respectivamente).

As variáveis ambientais temperatura e umidade relativa do ar no interior do galpão foram medidas com termômetro

Tabela 1 - Composição percentual e nutricional calculada e balanço eletrolítico das rações experimentais

\begin{tabular}{|c|c|c|c|c|c|c|}
\hline \multirow[t]{2}{*}{ Ingrediente } & \multicolumn{6}{|c|}{ Nível de cloro (\%) } \\
\hline & 0,07 & 0,12 & 0,17 & 0,22 & 0,27 & 0,32 \\
\hline Milho & 56,83 & 56,90 & 57,00 & 56,97 & 56,81 & 56,65 \\
\hline Farelo de soja & 33,22 & 33,20 & 33,19 & 33,20 & 33,23 & 33,25 \\
\hline Óleo de soja & 2,28 & 2,25 & 2,22 & 2,23 & 2,28 & 2,34 \\
\hline Calcário & 5,54 & 5,54 & 5,54 & 5,54 & 5,54 & 5,54 \\
\hline Fosfato bicálcico & 1,25 & 1,25 & 1,25 & 1,25 & 1,25 & 1,25 \\
\hline Suplemento vitamínico + mineral $^{1}$ & 0,50 & 0,50 & 0,50 & 0,50 & 0,50 & 0,50 \\
\hline Cloreto de amônia & 0,00 & 0,00 & 0,00 & 0,03 & 0,11 & 0,19 \\
\hline Bicarbonato de sódio & 0,31 & 0,19 & 0,07 & 0,00 & 0,00 & 0,00 \\
\hline Sal comum & 0,06 & 0,15 & 0,23 & 0,28 & 0,28 & 0,28 \\
\hline \multirow[t]{2}{*}{ Total } & 100,0 & 100,0 & 100,0 & 100,0 & 100,0 & 100,0 \\
\hline & \multicolumn{6}{|c|}{ Composição nutricional calculada } \\
\hline Energia metabolizável (kcal/kg) & 2.900 & 2.900 & 2.900 & 2.900 & 2.900 & 2.900 \\
\hline Proteína bruta (\%) & 20,00 & 20,00 & 20,00 & 20,00 & 20,00 & 20,00 \\
\hline Lisina $(\%)$ & 1,07 & 1,07 & 1,07 & 1,07 & 1,07 & 1,07 \\
\hline Metionina + cistina (\%) & 0,74 & 0,74 & 0,74 & 0,74 & 0,74 & 0,74 \\
\hline Metionina (\%) & 0,42 & 0,42 & 0,42 & 0,42 & 0,42 & 0,42 \\
\hline Treonina (\%) & 0,78 & 0,78 & 0,78 & 0,78 & 0,78 & 0,78 \\
\hline Triptofano (\%) & 0,25 & 0,25 & 0,25 & 0,25 & 0,25 & 0,25 \\
\hline Cálcio (\%) & 2,50 & 2,50 & 2,50 & 2,50 & 2,50 & 2,50 \\
\hline Fósforo disponível (\%) & 0,35 & 0,35 & 0,35 & 0,35 & 0,35 & 0,35 \\
\hline Sódio (\%) & 0,15 & 0,15 & 0,15 & 0,15 & 0,15 & 0,15 \\
\hline Cloro (\%) & 0,07 & 0,12 & 0,17 & 0,22 & 0,27 & 0,32 \\
\hline Potássio (\%) & 0,78 & 0,78 & 0,78 & 0,78 & 0,78 & 0,78 \\
\hline Balanço eletrolítico (mEq/kg) & 245,44 & 231,25 & 217,51 & 203,96 & 189,09 & 174,18 \\
\hline
\end{tabular}


de máxima e mínima e psicrômetro, respectivamente. Os dados foram registrados diariamente e as leituras realizadas às $8 \mathrm{~h}$ e às $16 \mathrm{~h}$. Ao final de cada período experimental, foram calculadas as médias das temperaturas máximas e mínimas e os valores de umidade relativa do ar.

Inicialmente, as aves foram pesadas, separadas de acordo com o peso médio e alojadas em gaiolas de postura $(33 \mathrm{~cm} \times 23 \mathrm{~cm} \times 16 \mathrm{~cm})$ com coletor de ovos de acordo com os tratamentos utilizados. Os parâmetros avaliados foram consumo de ração (g/ave/dia), porcentagem de postura (\%/ave/dia), peso do ovo (g), massa de ovo (g/ave/dia), conversão alimentar (g/g) e consumo de água (mL/ave/dia).

As rações foram pesadas e fornecidas em comedouros tipo calha. Depois de cada período experimental, foram pesadas as sobras para obtenção do consumo médio de ração.

Para determinar o consumo de água, as aves recebiam água em bebedouros para pássaros adaptados com capacidade para $500 \mathrm{~mL}$ de água. Diariamente, às $8 \mathrm{~h}$, fazia-se a medição da sobra de água, utilizando-se proveta de precisão com capacidade de $1 \mathrm{~L}$, para determinação do consumo médio de água, calculada pela diferença entre o oferecido e a sobra.

O programa de luz utilizado nessa fase foi contínuo, com 16 horas de luz (natural e artificial). A iluminação artificial foi feita com lâmpadas fluorescentes de 40 watts. A coleta de ovos foi feita diariamente às $8 \mathrm{~h}$ em bandejas de papelão para cálculo da produção de ovos por repetição no final de cada período experimental.

O peso médio do ovo foi obtido pelo cálculo do peso total de ovos coletado dividido pelo número de ovos total coletado por repetição em cada período. A pesagem foi feita uma vez na semana em balança eletrônica com precisão de 0,01 g. Com os dados do peso médio do ovo, foi calculada a massa do ovo multiplicando-se o número de ovos produzidos pelo peso médio do ovo para cada repetição e em cada período. A conversão alimentar foi calculada dividindo-se o consumo de ração pela massa de ovo.

A análise de qualidade dos ovos foi realizada uma vez por semana durante todo o período experimental. Para isso, os ovos oriundos das aves provenientes de cada repetição eram coletados, contados e pesados por repetição. Três deles eram selecionados aleatoriamente, determinando inicialmente a gravidade específica (GE) dos ovos utilizando-se os procedimentos descritos por Freitas et al. (2004), onde foi montado sobre balança de precisão (0,01 g) um sistema de pesagem dos ovos para obtenção do peso do ovo no ar e na água. Os valores do peso do ovo no ar e na água foram anotados para o cálculo da gravidade específica, por meio da equação $\mathrm{GE}=\mathrm{PO} /(\mathrm{PA} \times \mathrm{F})$, em que: $\mathrm{PO}=$ peso do ovo no ar; PA = peso do ovo na água; e $\mathrm{F}=$ fator de correção da temperatura.

Em seguida, os ovos foram quebrados sobre uma superfície de vidro para determinação da altura do albúmen com o uso de um micrômetro de profundidade. Os dados da altura do albúmen e do peso dos ovos foram utilizados no cálculo das UH por meio da equação $\mathrm{UH}=100 \log (\mathrm{H}+7,57$ $-1,7 \mathrm{~W}^{0,37}$ ), em que: $\mathrm{H}=$ altura do albúmen (mm) e $\mathrm{W}=$ peso do ovo (g).

Após a determinação da altura do albúmen, as gemas foram separadas e pesadas em balança de precisão $(0,01 \mathrm{~g})$ e as cascas dos ovos lavadas e postas para secar por um período de 48 horas e posteriormente pesadas. As porcentagens de gema e casca foram obtidas pela relação entre o peso de cada porção e o peso do ovo e a porcentagem de albúmen, por diferença: \% albúmen = $100-(\%$ gema $+\%$ casca).

Para avaliar os efeitos dos níveis de cloro na ração sobre a digestibilidade dos nutrientes e umidade das excretas, aos 173 dias de idade das aves (25 semanas), iniciou-se a coleta total de excretas por quatro dias. As excretas foram coletadas duas vezes ao dia, no início da manhã e ao final da tarde, e encaminhadas ao laboratório, onde foram secas em estufa de ventilação forçada a $55^{\circ} \mathrm{C}$ por 72 horas. Em seguida, as amostras foram trituradas em moinho tipo faca e, assim como as rações experimentais, foram acondicionadas em frascos e encaminhadas ao laboratório para determinação dos teores de matéria seca, nitrogênio e energia bruta, de acordo com metodologia descrita por Silva \& Queiroz (2002)

Com base nos resultados laboratoriais, foram calculados a umidade das excretas (\%), os coeficientes de digestibilidade da matéria seca, nitrogênio e energia bruta e os valores de energia metabolizável aparente e aparente corrigida das rações.

As análises estatísticas foram realizadas utilizando-se o programa Statistical Analysis System (SAS, 2000) e, para que as exigências de cloro fossem estimadas, os dados foram submetidos à análise de regressão.

\section{Resultados e Discussão}

As médias de temperatura ambiente mínima e máxima e umidade relativa no galpão durante o experimento foram $25,7{ }^{\circ} \mathrm{C} \pm 1,31$ e $28,5^{\circ} \mathrm{C} \pm 1,56$ e $\pm 87,7 \%$, respectivamente.

Conforme a análise dos dados, o consumo de ração (g/ave/dia), o consumo de água (mL/ave/dia), a porcentagem de postura (\%), o peso do ovo (g), a massa de ovo (g/ave/dia) e a conversão alimentar (g/g) não variaram significativamente entre os níveis de cloro testados (Tabela 2). Conforme os 
resultados, em rações para codornas em postura formuladas com milho e farelo de soja, contendo $0,15 \%$ de sódio e $0,78 \%$ de potássio, é possível utilizar níveis de cloro entre 0,07\% e $0,32 \%$ sem prejudicar o desempenho das aves.

A ausência de efeitos significativos dos níveis de cloro sobre o consumo de ração também relatada por Ribeiro et al. (2007) em estudo sobre as exigências de sódio e cloro para codornas japonesas em postura (65 dias de idade) utilizando os níveis $0,08,0,18,0,28$ e 0,38\% de cloro na ração. Entretanto, esses pesquisadores observaram efeito quadrático dos níveis de cloro sobre a produção de ovos, o peso do ovo e a conversão alimentar por massa e observaram melhora no desempenho com o aumento do cloro em níveis superiores a $0,08 \%$ e piora em níveis acima de $0,25 \%$ e $0,26 \%$ para a produção de ovos e conversão alimentar por massa de ovos, respectivamente. Segundo esses mesmos autores, níveis dietéticos baixos ou elevados de cloro na ração podem levar, respectivamente, a alcalose e acidose metabólica, efeitos provavelmente responsáveis pela queda de desempenho das codornas nos níveis extremos de cloro nas rações, uma vez que, nessas condições, ocorrerão alterações do equilíbrio acidobásico do organismo das aves. Entretanto, neste trabalho, o menor nível de cloro testado $0,07 \%$ está abaixo do utilizado pelos pesquisadores e não promoveu redução significativa no desempenho. Dessa forma, pode-se inferir que outros fatores contribuíram para a adaptação das aves as alterações do nível de cloro na ração.
Na literatura, as informações sobre os efeitos dos níveis de cloro sobre os parâmetros de desempenho de poedeiras comerciais também têm sido variáveis. Têm-se reportado ausência de efeitos significativos dos níveis de cloro sobre o consumo de ração, a porcentagem de postura e o peso dos ovos (Hess \& Britton, 1989) e efeito linear decrescente na conversão alimentar com o aumento dos níveis de cloro (Murakami et al., 2001b). Faria et al. (2000) não observaram diferenças significativas no desempenho de poedeiras alimentadas com ração contendo $0,16 \%$ ou $0,22 \%$ de $\mathrm{Cl}$ e $0,16 \%$ de $\mathrm{Na}$ e $0,22 \%$ de $\mathrm{K}$. Nessas pesquisas não foram relatados, no entanto, os mecanismos que estariam envolvidos nos efeitos do cloro sobre o desempenho das poedeiras.

Na avicultura, o efeito do cloro sobre a ingestão de água por codornas é pouco conhecido. Contudo, semelhante ao observado nesta pesquisa, Borges et al. (1999) e Mushtaq et al. $(2005 ; 2007)$ não notaram efeito significativo dos níveis de cloro avaliados sobre a ingestão de água.

Conforme os resultados obtidos no ensaio de metabolismo, a umidade das excretas, os coeficientes de digestibilidade da matéria seca, do nitrogênio, da energia bruta e os valores de energia metabolizável aparente e aparente corrigida para nitrogênio das rações não foram influenciados significativamente pelos níveis de cloro avaliados (Tabela 3).

Normalmente, as variações na umidade das excretas das aves associadas a mudanças dos eletrólitos da ração

Tabela 2 - Consumo de ração, consumo de água, porcentagem de postura, peso do ovo, massa de ovos e conversão alimentar de codornas em postura

\begin{tabular}{|c|c|c|c|c|c|c|c|c|}
\hline & \multicolumn{6}{|c|}{ Nível de cloro (\%) } & \multirow[b]{2}{*}{ Regressão } & \multirow[b]{2}{*}{ CV (\%) } \\
\hline & 0,07 & 0,12 & 0,17 & 0,22 & 0,27 & 0,32 & & \\
\hline Consumo de ração (g/ave/dia) & 21,90 & 21,88 & 22,06 & 21,83 & 21,95 & 22,00 & NS & 4,71 \\
\hline Porcentagem de postura (\%) & 86,85 & 88,67 & 90,45 & 90,45 & 92,44 & 90,89 & NS & 6,35 \\
\hline Peso do ovo (g) & 10,34 & 10,03 & 10,22 & 10,24 & 10,21 & 10,16 & NS & 2,44 \\
\hline Massa de ovo (g/ave/dia) & 8,99 & 8,88 & 9,25 & 9,26 & 9,44 & 9,23 & NS & 6,44 \\
\hline Conversão alimentar (g/g) & 2,45 & 2,48 & 2,39 & 2,36 & 2,32 & 2,40 & NS & 5,44 \\
\hline
\end{tabular}

NS - não-significativo $(\mathrm{P}<0,05)$; $\mathrm{CV}$ - coeficiente de variação.

Tabela 3 - Umidade das excretas, coeficientes de digestibilidade da matéria seca, do nitrogênio, da energia bruta, energia metabolizável aparente e aparente corrigida das rações de codornas

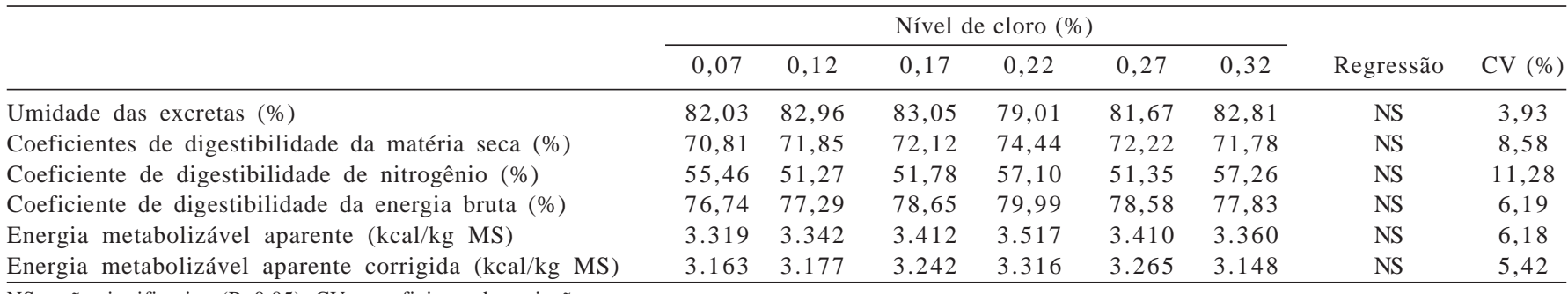

NS - não significativo $(\mathrm{P}<0,05)$; CV - coeficiente de variação. 
são ocasionadas pelo aumento da redução no consumo de água pelas aves na tentativa de manter a homeostase corporal. Dessa forma, como as codornas não apresentaram variações na ingestão de água, em razão das alterações do nível de cloro da ração, a ausência de variações significativas na umidade das excretas era esperada (Vena et al., 1990).

Estudando a exigência de cloro e sódio para poedeiras comerciais, Murakami et al., (2001b) também não verificaram influência significativa do nível de cloro sobre a umidade das excretas das aves. Segundo Rondon et al. (2001) e Murakami et al. (2001a) quando o nível de cloro da ração está em proporção adequada ao nível de sódio, não há aumentos significativos na excreção renal, consequentemente, não ocorre aumento na umidade das excretas. Por sua vez, Mushtaq et al. (2007) relataram que a umidade da cama tende a diminuir com o aumento dos níveis de cloro das rações.

Nesse contexto, os efeitos dos níveis de cloro da ração sobre a umidade das excretas das codornas observadas nesta pesquisa corroboram as afirmativas de outros pesquisadores de que, possivelmente, a umidade das excretas das aves não está em função do nível isolado de cloro da ração e sim de um efeito acumulativo e interativo desse íon com outros íons, como o sódio e o potássio (Mushtaq et al., 2005). Também é possível que a variação do nível de cloro, na presente pesquisa, não tenha sido suficiente para alterar a interação entre esses íons da ração de forma que ocorresse desequilíbrio osmótico nas codornas.

Em relação à metabolização dos nutrientes da ração, os resultados demonstraram que os níveis de cloro testados $(0,07$ a $0,32 \%)$ não influenciaram significativamente a capacidade das codornas em aproveitar os nutrientes da ração de postura, formulada com milho e farelo de soja e contendo $0,15 \%$ de sódio e $0,78 \%$ de potássio.

Apesar de o cloro participar na composição do ácido clorídrico, na ativação da amilase intestinal e no transporte ativo dos aminoácidos e da glicose (Andriguetto et al., 1990), na literatura, são escassas as informações sobre a influência isolada desse nutriente no aproveitamento dos nutrientes da ração. É possível que a manutenção de relações favoráveis entre o cloro e os demais íons da ração seja determinante no aproveitamento dos nutrientes, e não sua ação isolada. Entretanto, essa hipótese somente pode ser esclarecida com a realização de novas pesquisas.

Em geral, os resultados obtidos no ensaio de metabolismo justificaram o desempenho semelhante entre as codornas submetidas aos diferentes níveis de cloro na ração, visto que o desempenho dessas aves depende da ingestão e do aproveitamento dos nutrientes da ração.

$\mathrm{Na}$ análise dos componentes e da qualidade dos ovos, a porcentagem de gema (\%), de albúmen (\%) e casca (\%) e a unidade Haugh não foram influenciadas significativamente pelos níveis de cloro da ração. Entretanto, houve aumento linear na gravidade específica ( $\left.\hat{Y}=1,074+0,015 x ; r^{2}=0,21\right)$ com o acréscimo de cloro na ração (Tabela 4).

A gravidade específica dos ovos está relacionada à qualidade da casca e, embora não tenha apresentado diferença significativa, a proporção de casca dos ovos aumentou com os níveis de cloro na ração, e este aumento pode ter influenciado na determinação da gravidade, principalmente devido ao baixo coeficiente de variação dos dados obtidos. Por outro lado, os valores de gravidade específica dos ovos das aves que receberam o menor nível de cloro podem ser considerados satisfatórios se comparados aos relatados na literatura (Pizzolante et al., 2006).

Estudando as exigências de sódio e cloro de codornas japonesas Ribeiro et al. (2007) verificaram efeito quadrático dos níveis de cloro da ração sobre a gravidade específica dos ovos, que aumentou até o nível estimado de 0,21\% de cloro, piorando em níveis mais elevados. De acordo com esses autores, a melhora na qualidade da casca associada ao cloro se deve à acidificação do bolo alimentar, que aumenta a solubilidade e absorção de minerais como o cálcio e o fósforo, que são fundamentais para a formação e a qualidade da casca dos ovos. Keshavarz \& Austic (1990), no entanto, verificaram que manipulações da dieta de poedeiras que elevam sua carga ácida são prejudiciais à qualidade da casca dos ovos por aumentar a excreção de cálcio. Faria et al. (2000) observaram melhora na qualidade da casca com a redução de $0,22 \%$ para $0,16 \%$ de cloro na ração de poedeiras.

Tabela 4 - Componentes de qualidade do ovo das codornas alimentadas com rações contendo diferentes níveis de cloro

\begin{tabular}{lcccccccr}
\hline & \multicolumn{9}{c}{ Nível de cloro (\%) } & Regressão & CV (\%) \\
\cline { 2 - 5 } & 0,07 & 0,12 & 0,17 & 0,22 & 0,27 & 0,32 & NS & 2,47 \\
Gema (\%) & 29,40 & 29,95 & 29,61 & 30,06 & 29,34 & 30,02 & NS & 1,27 \\
Albúmen (\%) & 62,50 & 61,45 & 61,87 & 61,51 & 62,19 & 61,39 & NS & 2,89 \\
Casca (\%) & 8,26 & 8,53 & 8,53 & 8,49 & 8,41 & 8,55 & NS & 1,77 \\
Unidades Haugh & 90,37 & 89,76 & 90,03 & 89,63 & 90,88 & 90,52 & L* \\
Gravidade específica & 1,075 & 1,076 & 1,076 & 1,078 & 1,078 & 1,079 & 0,24 \\
\hline
\end{tabular}

L - efeito linear; Q - efeito quadrático; * significativo $(\mathrm{P}<0,05)$; NS - não-significativo; CV - coeficiente de variação. 
Os balanços eletrolíticos das dietas experimentais foram 245,44; 231,25;217,51; 203,96; 189,09 e 174,18 mEq/kg. Para melhor qualidade do ovo e digestibilidade em codornas na fase de produção (17 a 32 semanas de idade), o balanço eletrolítico da ração pode variar de 245,44 a 174,18 mEq/kg, pois não prejudica o desempenho dessas aves.

\section{Conclusões}

Níveis de 0,07 até 0,32\% de cloro em rações à base de milho e farelo de soja para codornas na fase de produção não prejudicam o desempenho nem a qualidade de ovos.

\section{Referências}

ANDRIGUETTO, J.M.; PERLY, L.; MINARDI, I. et al. Nutrição animal. As bases e os fundamentos da nutrição animal: Os alimentos. 4.ed. São Paulo: Nobel, 1990. 395p.

BORGES, S.A.; ARIKI, J.; MORAES, V.M.B. et al. Relação (Na+K-Cl) na dieta inicial de frangos de corte durante o verão. In: REUNIÃO ANUAL DA SOCIEDADE BRASILEIRA DE ZOOTECNIA, 36., 1999, Porto Alegre. Anais... Porto Alegre: SBZ, 1999. (CD-ROM).

FARIA, D.E.; JUNQUEIRA, O.M.; SAKOMURA, N.K. et al. Influência de diferentes níveis de energia, vitamina D3 e relação sódio:cloro sobre o desempenho e a qualidade da casca dos ovos de poedeiras comerciais. Revista Brasileira de Zootecnia, v.29, n.2, p.467-475, 2000.

FREITAS, E.R.; SAKOMURA, N.K.; GONZALEZ, M.M. et al. Comparação de métodos de determinação da gravidade específica de ovos de poedeiras comerciais. Pesquisa Agropecuária Brasileira, v.39, n.5, p.509-512, 2004.

HESS, J.B.; BRITTON, W.M. The effect of dietary chloride or protein changes on eggshell pimpling and shell quality in late production leghorn hens. Nutrition Reports International, v.40, n.6, p.1107-1115, 1989.

KESHAVARZ, K.; AUSTIC, R.E. Effect of dietary minerals on acid-base balance and eggshell quality in chickens. Jornal Nutricion, v.120, p.1360-1369, 1990.

MONGIN, P. Electrolytes in nutrition: a review of basic principles and practical application in poultry and swine. In: IMC NUTRITION CONFERENCE, 3., 1980, Melbourne. Proceedings... Orlando: IMC, 1980. p.1-15.

MURAKAMI, A.E.; RONDÓN, E.O.O.; MARTINS, E.N. et al. Sodium and chloride requirements of growing broiler chickens (twenty-one to forty-two days of age) fed cornsoybean diets Poultry Science, v.80, p.289-294, 2001a.

MURAKAMI, A.E.; FAQUINELLO, P.; SAKAMOTO, M.I. et al. Exigência nutricional de sódio e cloro para poedeiras comerciais. Revista Brasileira de Ciência Avícola, suplemento 3, p.52, 2001b.

MUSHTAQ, T.; SARWAR, M.; NAWAZ, H. et al. Effect and interactions of dietary sodium and chloride on broiler starter performance (hatching to twenty-eight days of age) under subtropical summer conditions. Poultry Science, v.84, p.1716-1722, 2005.

MUSHTAQ, T.; MIRZA, M.A.; ATHAR, M. et al. Dietary sodium and chloride for twenty-nine to forty-two-day-old broiler chickens at constant electrolyte balance under subtropical summer conditions. Journal of Applied Poultry Research, v.16, p.161-170, 2007.

NATIONAL RESEARCH COUNCIL - NRC. Nutrient requirements of poultry. 9.ed. Washington: National Academy of Science, 1994. p.155.

PIZZOLANTE, C.C.; SALDANHA, E.S.P.B.; GARCIA, E.A. et al. Níveis de sal comum em rações de codornas japonesas (Coturnix coturnix japonica) em final de produção. Ciência Animal Brasileira, v.7, n.2, p.123-130, 2006.

RIBEIRO, M.L.G.; SILVA, J.H.V.; SOUSA, J.B. et al. Exigências de sódio e de cloro e efeitos sobre o desempenho produtivo de codornas japonesas (Coturnix coturnix japonica). Revista Brasileira de Ciência Avícola, suplemento 9, p.145, 2007. RODRIGUES V.P.; COSTA, F.G.P.; GOULART, C.C. et al. Exigência de cloro para codornas japonesas de 1 a 21 dias de idade. In: ZOOTEC, 2008, João Pessoa. Anais... João Pessoa, 2008. (CD-ROM).

RONDÓN, E.O.O.; MURAKAMI, A.E.; FURLAN, A.C. et al. Exigências nutricionais de sódio e cloro e estimativa do melhor balanço eletrolítico da ração para frangos de corte na fase préinicial (1 a 7 dias de idade). Revista Brasileira de Zootecnia, v.29, n.4, p.1162-1166, 2000.

RONDÓN, E.O.O.; MURAKAMI, A.E.; FURLAN, A.C. et al. Sodium and chloride requirements of young broiler chickens fed cornsoybean diets (one to twenty-one days of age). Poultry Science, v.80, p.592-598, 2001.

ROSTAGNO, H.S. Tabelas brasileiras para aves e suínos: composição de alimentos e exigências nutricionais. 2.ed. Viçosa, MG: UFV. p.186, 2005.

SILVA, D.J.; QUEIROZ, A.C. Análise de alimentos: métodos químicos e biológicos. 3.ed. Viçosa, MG: Editora UFV, 2002. 165p.

STATISTICAL ANALYSES SYSTEM - SAS. SAS/STAT: User's guide. Version 7.0. Cary: 2000. 325p.

VENA, V.E.; LAC, T.H.; WIDEMAN, R.F. Dietary sodium, glomerular filtration rate, autorregulation and glomerular size distribution profiles in domestic fowl (Gallus gallus). Journal of Comparative Physiology, v.160, n.1, p-7-16, 1990. 